\title{
College Student Depression: Counseling Billy
}

By: A. Keith Mobley

This is the accepted version of the following article:

Mobley, A. K. (2008) College student depression: Counseling Billy. Journal of College

Counseling, 11(1), 87-96. doi: 10.1002/j.2161-1882.2008.tb00026.x,

which has been published in final form at http://dx.doi.org/10.1002/i.2161-

1882.2008.tb00026.x.

***@ American Counseling Association. Reprinted with permission. No further reproduction is authorized without written permission from the American Counseling Association \& Wiley. This version of the document is not the version of record. Figures and/or pictures may be missing from this format of the document. ***

\begin{abstract}
:
A substantial portion of the college student population experiences affective disorders. This case study presents the conceptualization, course of treatment, and outcomes for a male college student presenting for counseling with depression. A review of Adlerian, cognitive-behavioral, and Gestalt techniques is provided.
\end{abstract}

Keywords: Counseling | College students | Depression | Case study

\section{Article:}

Affective disorders, especially depression, constitute a large portion of the issues presented in college counseling centers (Apfel, 2003). Given the acceleration of identity development and the myriad stressors during the college years, it is not surprising that many students experience their first depressive episode, which may result in impaired social functioning, substance abuse, and academic difficulties (Michael, Huelsman, Gerard, Gilligan, \& Gustafson, 2006). Because of the wide variance in the etiology of depression and individual experiences, no single treatment or combination of interventions can be generalized for use with every client situation.

Consequently, it is critical for college counselors to be familiar with multiple types of interventions, informed by both the counseling literature and by other practitioners in the field. A case study can be a useful way to illustrate interventions, demonstrate the intentionality and flexibility needed in adapting research findings, and empower practicing counselors who might otherwise be isolated from the work of other practitioners. This case study presents an integrated approach to the multiple facets encountered when counseling one specific male college student who was experiencing depression.

\section{Introduction of the Counselor}


The service provider (the author) is a clinical assistant professor in the counselor education department at a midsize, U.S. university. This counselor teaches and provides supervision in the academic department but primarily has the responsibility of directing clinical activities within the institution's in-house counseling clinic. He also maintains a caseload of five to six clients. This male counselor has a doctorate in counseling and counselor education, has voluntary certifications as a National Certified Counselor and Approved Clinical Supervisor, holds a state license to practice counseling, and has approximately 11 years of counseling experience in various settings. This provider integrates theoretical orientations in ways that fit the developmental status, stage of counseling, and needs or goals of the client. Generally, this counselor integrates person-centered, Adlerian, and cognitive-behavioral intervention and evaluation approaches. Additionally, Gestalt techniques are frequently used when clients present with existential goals or what is referred to as unfinished business. Furthermore, the provider adheres to the scientist-practitioner tradition of counseling, which emphasizes the use of practice-based research to inform interventions, accurately assess and conceptualize client issues, and measure progress and outcomes.

\section{Client Introduction and Case Conceptualization}

The client (who will be referred to by the pseudonym Billy) is a 20-year-old, White, heterosexual man presenting for counseling with depressive symptoms, feelings of being "overwhelmed” with anxiety about school performance, and value conflicts pertaining to his choice of major. Billy is a first-generation college student and was awarded a teaching fellowship to attend the university in recognition of achievements as a high school student and his interest in becoming a teacher in the rural community in which he was reared. Billy's family of origin was considered socioeconomically as lower middle class and consisted of both biological parents and an older sister. Billy reported a history of depression on the maternal side of his family, including his grandmother; an uncle; and, perhaps most significantly, his mother during his elementary school years. During his mother's experience with depression, Billy reported that she displayed a negative and sometimes avoidant parenting style, causing him to perceive difficulty in achieving her approval. Billy also reported being ostracized by his peers in elementary and middle school, which created significant distress and isolation for him until his midteens. Otherwise, Billy's developmental history was unremarkable, with all developmental milestones met within normal limits and no reported history of trauma or substance use. This client did report some hopefulness that counseling would assist him, based on previous experiences with a counselor during his challenging childhood years.

Billy was referred for counseling by his family physician, who provided aprovisional diagnosis of Major Depressive Disorder (American Psychiatric Association [APA], 1994) to describe his symptoms and prescribed an antidepressant medication to alleviate his primary mood symptoms. The client denied suicidal ideation or recurrent thoughts of death. Billy regarded low self-esteem and the dissonance related to his choice of major field of study as the primary sources of his depressed mood. 
To fully contextualize this client, one needs to take into account the many protective factors. Billy presented as having above-average intelligence for his age and said he enjoyed using metaphors and contemplating and articulating abstract concepts. In fact, he was very creative in using adages and analogies to convey ideas or the quality of his experiences. He was exceptionally creative and imaginative, and his primary peer group played fantasy role-playing board and video games on a regular basis. He had interests in science, subscribing to popular science magazines, watching documentaries, and drawing inventions. Another main interest of this client was martial arts, which he had recently ceased practicing because of school and work conflicts.

His initial interview made it apparent that the primary issue of mood dysphoria was generated and perpetuated by negative cognitions about his self-worth and abilities and was related to his career choice originating from the familial and cultural context (i.e., family messages). Billy maintained several faulty assumptions related to his priority of perfectionism. These assumptions were reflected in statements such as "Small mistakes have amplified consequences" and "I am what I achieve, and achievements determine worth.” Ultimately, these assumptions had led to the development of an unrealistic perception of self, evidenced by the consistent presence of negative self-talk and irrational beliefs. These assumptions and beliefs contributed to his depressive symptoms and feelings of insecurity and confusion, particularly within his identity as a student.

In addition to the need for perfection, Billy was second-guessing his choice of and self-efficacy as an education major. For Billy, the decision to become a teacher seemed to be compelled by his family's messages about social interest: To be important, one must assist others in direct and instrumental ways (e.g., teaching). Instead of following his own ideals of social interest related to science, creativity, and fantasy, he had selected to follow his familial message.

The combination of this dissonance between family messages and current interests and a strong need for perfection had resulted in the symptoms of depression that Billy was experiencing. Therefore, goals for counseling - arrived at through a collaboration between clinician and client-were to identify and confront the faulty logic that had led to negative self-talk, modify core beliefs (i.e., perfection and ways to achieve social interest), and sufficiently encourage and instill behavioral skills to relieve his symptoms of depression and improve self-concept.

Two other vital, although secondary, components pertaining to the conceptualization of Billy's counseling needs were his readiness to change and developmental stage (Chickering \& Reisser, 1993). According to the Transtheoretical Model of Change (Prochaska \& DiClemente, 1992), this client was in the contemplation stage, an early stage of decision making characterized by the client's awareness of the pros and cons of changing, but ambivalence about or ineptitude at planning or taking action. His symptoms of impaired concentration and lack of energy further limited his ability to develop and implement a course of change on his own. The second salient component was this client's developmental stage. According to Chickering and Reisser, college 
students of traditional age develop along seven vectors: (a) developing competence, (b) managing emotions, (c) moving through autonomy to interdependence, (d) developing mature interpersonal relationships, (e) establishing identity, (f) developing purpose, and (g) developing integrity. Although all seven of these facets of development were salient for this client, it seemed that Billy had reached an impasse at managing emotions, establishing identity, and developing purpose.

By conceptualizing this client's needs according to presenting problems, strengths, and developmental tasks, interventions were geared not merely to ameliorate the current distress but also to provide opportunities to foster psychological growth and optimize his functioning and overall well-being. Although college counselors usually consider a student's symptoms diagnostically when conceptualizing a client situation, taking into account multiple aspects of the person's adjustment is also important to the overall understanding of the client's needs and is required to inform evidenced-based interventions.

\section{Diagnostic Impressions}

When the client entered counseling, his symptoms warranted a provisional diagnosis of 296.32 Major Depressive Disorder (APA, 1994) according to the family physician who made the referral and had already prescribed an antidepressant medication to manage the mood symptoms. Upon presentation, clinical interview, and the gathering of psychometric data using the Beck Depression Inventory-II (BDI-II; Beck, Steer, \& Brown, 1996), the diagnosis pertaining to Billy's symptoms was confirmed. The main symptomatic criteria experienced by this client were depressed mood, significant weight gain (>5\%), sleep disturbance, loss of energy, inappropriate guilt, and diminished ability to think and/or concentrate. Billy also had two other issues of clinical significance that could have been conceptualized diagnostically: V62.3 Academic Problem and 313.82 Identity Problem (APA, 1994); however, this provider conceptualized these issues as hallmarks of developmental tasks rather than as clinical conditions impairing functioning.

\section{Counseling Method and Course of Treatment}

\section{Goals and Interventions for Change}

On the basis of the presenting concerns and assessment results, cognitive-behavioral therapy was selected as a clinically sound, evidence-based intervention that is considered to be effective during both acute and continuation phases of treatment of depression (Vittengl, Clark, Dunn, \& Jarrett, 2007). Furthermore, cognitive techniques are conducive for moving clients from early stages in the Transtheoretical Model of Change (Prochaska \& DiClemente, 1992) to concrete action (Petrocelli, 2001). Thus, the overarching goals for Billy included abatement of depressive symptoms and increased academic performance. To achieve these specific outcomes, the counselor used cognitive-behavioral therapy interventions with goals of creating insight into patterns of behavior or thinking that were contributing to his depression, replacing maladaptive 
patterns with constructive alternatives, and improving coping and emotional regulation skills (see Appendix). Furthermore, the treatment plan included insight-oriented goals related to unresolved issues from childhood. In addition to the concrete interventions, another critical component of the treatment plan was to evaluate the course and outcomes of counseling. Throughout, the counselor collaborated with the client in determining the course of therapeutic action.

\section{Course of Counseling}

To help assess the effectiveness of this treatment plan, the counselor used two measures of depression to quantify Billy's experience throughout counseling. The BDI-II, which consists of two subscales (Cognitive and Physical), was used at regular intervals throughout counseling. To monitor progress and direct each session, Billy agreed to rate the relative intensity of his feelings of depression and his anxiety using a Subjective Unit of Distress scale, with 100 as the highest level of distress and 0 as the lowest level, or absence, of distress. In all, Billy attended 21 individual counseling sessions.

Generally, this client was able to make significant gains in the remission of depressive symptoms and the normalization of specific components of depression, both physical (e.g., increased energy, improved sleep, weight maintenance) and psychological (e.g., concentration, anxiety, emotional regulation). This, in turn, led to improved academic performance and a more positive appraisal of self and external circumstances. These changes were recorded throughout counseling using the BDI-II, with Billy endorsing an initial rating of 35 (severe depression) at intake and a rating of 5 (mild depression) at the last session (see Figure 1). The client's Subjective Unit of Distress ratings (see Figure 1) have more variation across sessions but also carried more salience for the client, in that the ratings he selected could provide information about current events or stressors and assist in directing the focus or content of the sessions. The primary achievements during counseling occurred through a supportive therapeutic relationship and the client's acquisition of emotional and cognitive regulation skills. Specifically, at the end of counseling, this client was able to (a) identify, label, and express emotions appropriately; (b) develop a more realistic pattern of thinking and of self-appraisal; and (c) address some faulty assumptions in his core beliefs. This client also reported many secondary gains, such as improved communication patterns with others, increased assertiveness, and increased involvement in meaningful activities.

Although the general course of counseling was positive and effective for this client, quantifiable outcome measures provide only one facet by which progress should be evaluated. The quality of Billy's experience with both the counseling relationship and the interventions used leads to a better understanding of the process of change and movement toward desired outcomes.

\section{The Counseling Process: Interventions and Movement}

The process of change is outlined according to specific stages experienced by the client during counseling, although this was not always a linear process. These include the initial stages of 
counseling, the Adlerian Lifestyle Assessment, and the implementation of cognitive and Gestalt interventions, respectively.

Initial stages of counseling. During the initial session, the structured tasks of informed consent and collection of intake data were accomplished. Subsequently, and for the remainder of counseling, emphasis was placed on the core conditions of unconditional positive regard, congruency, and empathy (Rogers, 1951), which were critical to providing Billy with emotional support, building rapport, reducing guilt or shame, and increasing client disclosure. Behavioral techniques to address the somatic components of depression were introduced in the initial stages of counseling, such as prescribing moderate exercise, offering strategies to regulate sleep, and addressing issues related to diet and nutrition. As counseling continued, these techniques increased in level of perceived risk and in the degree to which the client initiated his own goals. As a preliminary assessment and intervention to increase awareness, Billy was asked to begin observing and writing down some of the cognitive aspects of his depression, as well as to identify constructive ways of comforting or soothing himself. Billy was able to bring a short list of negative self-talk as well as reports of his follow-through on his successes and problems with strategies to address physical issues. During this stage, the counselor assumed a more directive role of problem solver in order to offer concrete solutions, provide encouragement, reframe successes, and reorient Billy toward lasting change. However, the client was an active participant with the counselor even at this more directive stage.

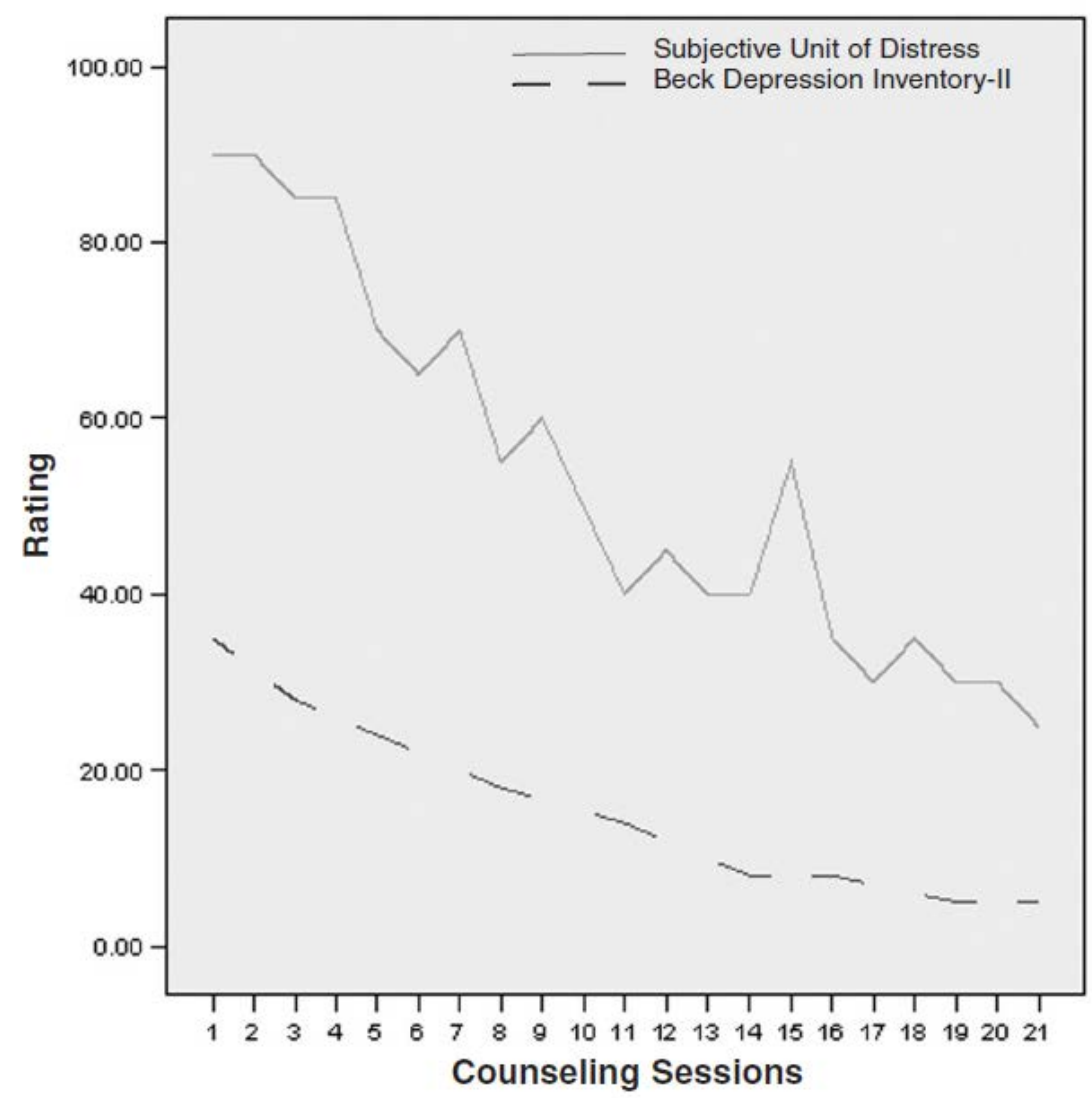


Figure 1. Graphical Report of Beck Depression Inventory-II and Subjective Unit of Distress Scores Throughout Counseling Sessions

Review of Adlerian Lifestyle Assessment. To assist with conceptualization, the counselor used an abbreviated Lifestyle Assessment (see Sweeney, 1998, for full description) as a homework assignment for Billy between Sessions 3 and 4. This assessment included multiple questions in the following categories: (a) his family constellation and perception of familial roles; (b) childhood experiences, ambitions, and peer group; and (c) early recollections and dreams. Each of these areas generated meaningful material for the interventions that were to be provided in subsequent sessions.

Combining his description of family, which included a distant relationship with his mother and generally tense or argumentative interactions among family members, with early childhood memories of "feeling lost," Billy viewed himself as a passive, irrelevant participant in his family. He indicated frequent attempts to avoid family interactions, particularly if conflict was present, and occasionally played the role of "peacekeeper" to evade conflict. A similar theme of selfperceived inferiority came out of his description of childhood experiences, ambitions, and peer group. Billy referred to himself as "sick all my life," referring to asthma and allergies that limited physical activity. Billy reported that he was viewed as "lazy" by his peer group and was teased and ostracized for not being able to participate in sports or physical activities. Consistent with this theme was an early recollection of being incapable of learning to tie his shoes or button his shirts and the negative messages of mastery that these experiences implied. Billy indicated that he internalized these early messages, which made it difficult for him to acquire the confidence at taking risks with new tasks or the social skills needed to assert himself. He did report being able to make some new connections between his childhood experiences and his current circumstances, realizing that this history had become a "lens" for him to see current events. This lens resulted in the negative beliefs and faulty assumptions that if he was unable to achieve perfection, then he was fundamentally unacceptable and terminally inferior to others, leading to his presenting symptoms of depression and dissonance with his family's imperatives regarding his college major.

Cognitive interventions. The presence of Beck's (1970) depressive cognitive triad was readily apparent to the counselor when meeting with this client. For example, Billy had negative appraisals and irrational beliefs about (a) self and life experiences ("I do not deserve to be in college"), (b) the future ("I will not pass my classes”), and (c) the world related to school ("There is no major for me"). These contributed to the development and maintenance of Billy's depression. To deal with these destructive cognitive patterns, the counselor implemented several interventions to address Billy’s discrete thoughts and core beliefs.

The ABC (activating event, belief, emotional consequences) theory of personality, as proposed by Ellis (1979), was introduced to Billy early in counseling using a white board and several examples from the counselor's experience. As a means of emphasizing the importance of 
cognitions, an experiment was conducted in the session by the counselor and client. In this experiment, Billy was asked to attempt four simple tasks in succession and report on his success with each. The tasks were (a) visualize his favorite color of blue, (b) experience rage, (c) rub his belly, and (d) pat his head. In this experiment, each of these simple tasks represented a domain of being: cognitions, emotions, and behavior. In this example, Billy verbalized understanding that he had mastery over both his thoughts and behaviors; however, Billy stated that he was not able to achieve intensity of rage but rather was only able to achieve the lower intensity emotion of “irritation.” When asked, Billy stated that he conjured this emotion by recalling the memory of a conflict with his roommate, in turn creating this emotional consequence. Billy then verbalized understanding of the ABC model, including his direct control over cognitions and actions and the mediating role thoughts may play in emotional regulation. After further facilitation and demonstration, Billy was able to take the initiative by providing multiple examples of disputing irrational, unrealistic, or negative beliefs or self-talk in this and subsequent sessions.

Another intervention that was often used to assist this client was the use of dominoes, which was consistent with Billy’s preference for metaphors. Dominoes were set up on a table in the counseling session room to represent the components of sequential events, whether behavioral, cognitive, or emotional, that had led to Billy's negative emotional consequences. Using an example of avoiding a professor who provided him negative but constructive feedback on a written assignment, Billy deconstructed the sequence leading to his avoidant reaction. In this example, Billy defined the dominoes as (a) procrastinating about doing the assignment, (b) a negative self-statement about his abilities, (c) a reminder of the core beliefs about perfection and school performance, (d) continued dissonance about his choice of major, and (e) additional negative self-statements regarding his ability and confidence in making adult choices. By making a concrete representation of the elements constituting his negative reactions, Billy was able to identify opportunities for altering the outcomes. In other words, Billy developed a visualization of each chance to arrest the domino effect by modifying any of the components, such as stopping an automatic thought, mediating an intense emotion, or implementing a behavioral skill. In addition to the practicality of identifying the interplay of these cognitive/affective/behavioral dominoes, this demonstration provided many opportunities to examine the origins of some of these components. For example, each of the messages that conveyed a core belief, or circumstances in which others may have second-guessed his abilities as a young student, was explored more fully. Ultimately, Billy was able to connect his negative self-talk to the messages he received from his mother during her depression and from his peers in elementary school, which helped to set the stage for then confronting and restructuring some fundamental, destructive beliefs.

The use of the in-session experiment and domino metaphor provided Billy with what he called a "word picture" to help him recollect these concepts and implement them in practice. Billy was able to demonstrate proficiency with these intrapersonal skills during the sessions and, by his report, outside of the sessions. 
Gestalt intervention. An empty-chair technique was used on two occasions to arouse emotions and to facilitate corrective emotional experiences. Specifically, Billy agreed to address the critical parent within himself by first confronting himself for maintaining unrealistic expectations for himself and then by for giving himself. These sessions were quite powerful for Billy, who was tearful and strained during the intervention. Billy described success at visualizing himself in the empty chair and bringing the emotions into the moment. Billy displayed a sense of calm subsequent to the event and reported a sense of relief and renewal at being able to separate the self-critical aspect of himself. Consistent with the goals of Gestalt therapy, this client increased awareness and ownership of his experiences and increased his acceptance of others.

\section{Conclusion}

Ultimately, this client was able to alter his emotional regulation skills and develop a new career path in the sciences. By implementing theoretical principles, such as the core conditions of counseling, an Adlerian conceptualization, and cognitive-behavioral techniques, this client was able to achieve constructive, measurable change. Specifically, change for Billy began with implementing behavioral homework to first address the physical components of his depression and, subsequently, practice new skills related to emotional regulation and personal self-efficacy. By conceptualizing this client's needs from a combined cognitive-behavioral and Adlerian perspective, his social interest, feelings of inferiority, negative self-worth, core beliefs, and faulty assumptions were identified. Last, cognitive components were used to help him identify the skills necessary to address cognitions at the surface and core levels. It is hoped that college counselors will gain ideas and a new perspective on counseling college students with depression from this example and will continue to collect intervention alternatives to address the wide variance of mood dysphoria experienced by today’s diverse college student population.

\section{References}

American Psychiatric Association. (1994). Diagnostic and statistical manual of mental disorders (4th ed.).Washington, DC: Author.

Apfel, J. L. (2003). Depression and its treatments: A college sample. Journal of College Student Psychotherapy, 18, 67-81.

Beck, A. T. (1970). The core problem in depression: The cognitive triad. In J. H. Masserman (Ed.), Depression: Theories and therapies (pp. 47-55). New York: Grune \& Stratton.

Beck, A. T., Steer, R. A., \& Brown, G. K. (1996). Manual for the Beck Depression Inventory II (BDI-II). San Antonio, TX: Psychological Corporation.

Chickering, A. W., \& Reisser, L. (1993). Education and identity (2nd ed.). San Francisco: Jossey-Bass. 
Ellis, A. (1979). Rational emotive therapy. In R. J. Corsini (Ed.), Current psychotherapies (2 ${ }^{\text {nd }}$ ed., pp. 185-229). Itasca, IL: Peacock.

Michael, K. D., Huelsman, T. J., Gerard, C., Gilligan, T. M., \& Gustafson, M. R. (2006).

Depression among college students: Trends in prevalence and treatment seeking. Counseling and Clinical Psychology Journal, 3, 60-70.

Petrocelli, J. V. (2001). Processes and stages of change: Counseling with the Transtheoretical Model of Change. Journal of Counseling \& Development, 80, 22-30.

Prochaska, J. O., \& DiClemente, C. C. (1992). The transtheoretical approach. In J. C. Norcross \& M. R. Goldfried (Eds.), Handbook of psychotherapy integration (pp. 300-334). New York: Basic Books.

Rogers, C. (1951). Client-centered therapy. Boston: Houghton Mifflin.

Sweeney, T. J. (1998). Adlerian counseling: A practitioner's approach (4th ed.). Bristol, PA: Accelerated Development.

Vittengl, J. R., Clark, L. A., Dunn, T. W., \& Jarrett, R. B. (2007). Reducing relapse and recurrence in unipolar depression: A comparative meta-analysis of cognitive behavioral therapy's effects. Journal of Consulting and Clinical Psychology, 75, 475-488.

\section{APPENDIX}

\section{Treatment Plan}

Long-term goals

1. Client will experience abatement of depressive symptoms, including improved mood, increased sleep regularity, improved concentration, and decreased anxiety.

2. Client will demonstrate improved coping and emotional regulation skills.

3. Client will gain insight into patterns of behavior or thinking that may contribute to his depression and replace patterns as possible with more constructive behavior or cognition.

4. Client will demonstrate increased academic performance.

Short-term objectives

1. Monitor and verbalize feelings of depression and related symptoms that impede in level of functioning

Intervention

a. Explore the client's history of depressed mood in the past through present 
b. Through an environment of trust, assist client in identifying, labeling, and expressing depressive symptoms

Method of evaluation

Client report, Beck Depression Inventory-II, Subjective Unit of Distress scale, session evaluation

2. Engage in physical and/or recreational activities to counter depressive symptoms

Intervention

a. Explore interests in recreational or athletic activities and assign client to participate in at least three activities per week and report results

Method of evaluation

Client report, journal

3. Identify distortions in thinking that contribute to depressed feelings

Intervention

a. Review ABC model and identify irrational thinking patterns

b. Use journal to inventory and dispute instances of automatic thoughts, distorted thinking, or negative self-talk

Method of evaluation

Client report, journal

4. Identify unresolved issues that may contribute to depression

Intervention

a. Explore client's unresolved conflicts with family and/or friends

b. Using the Lifestyle Assessment, assist client in understanding themes/patterns, faulty assumptions, and any discrepancies between social interests and decisions

Method of evaluation

Client report, Lifestyle Assessment

5. Take psychotropic medication as prescribed and report its effect and possible side effects Intervention 
a. Monitor and evaluate the client's prescription compliance of psychotropic medication, assessing the effectiveness of the medication on level of functioning, mood, and absence of suicidal ideation; consult with physician regularly

Method of evaluation

Client report, journal

Note. $\mathrm{ABC}=$ activating event, belief, emotional consequences. 